\title{
Comparative Study Regarding Efficacy of Radiofrequency Rhizotomy and the Microvascular Decompression in the Treatment of Trigeminal Neuralgia
}

\author{
ABDUL MAJID, MUHAMMAD FAROOQ, MUHAMMAD SHAKIR \\ ZUBAIR MUSTAFA KHAN, SAJID IQBAL \\ Department of Neurosurgery, PGMI/Lahore General Hospital, Lahore - Pakistan \\ DOI: https://doi.org/10.36552/pjns.v23i3.350
}

\begin{abstract}
Objective: Trigeminal neuralgia is the lancinating electric shock like pain because of neurovascular compression in trigeminal nerve distribution. We compared the efficacy of radiofrequency rhizotomy with microvascular decompression in terms of complete pain relief.
\end{abstract}

Material and Methods: The randomized controlled trial study was conducted in the neurosurgery department, LGH Lahore for a period of one year June 2017 to June 2018. A total of 110 patients were included and distributed into two groups, i.e. group-I who underwent radiofrequency rhizotomy (RFR) and group-II who underwent microvascular decompression (MVD). Follow-up of all the patients was assured up to six months. All the data were analyzed using S.P.S.S Ver. 23.0.

Results: There were $38(34.6 \%)$ male and $72(65.4 \%)$ female. Mean age was $51.25 \pm 8.80$ years. At the end of six months, in Group-I (RFR), Nineteen (34.5\%) patients were completely pain free, 25 (45.5\%) patients had significant pain relief, $7(12.7 \%)$ had mild improvement in the pain and $4(7.3 \%)$ patients had no improvement in the pain. In group-II (MVD), 30 (54.5\%) patients were completely pain free, 14 (25.5\%) had significant pain relief, $9(16.4 \%)$ had mild improvement and $2(3.6 \%)$ had no improvement in their pain (Chi-square $=6.49, p=$ 0.090).

Conclusion: Microvascular decompression had better results than a radiofrequency rhizotomy in patients presenting with trigeminal neuralgia regarding excellent pain relief and fewer complications.

Keywords: Microvascular decompression (MVD), Radiofrequency Rhizotomy (RFR), Trigeminal Neuralgia $T G N)$.

\section{INTRODUCTION}

Trigeminal neuralgia (TGN) is frequently occurring unbearable, debilitating painful condition in patients with advancing age, i.e. 50 to 60 years old and is caused by neurovascular compression in trigeminal nerve distribution. ${ }^{1,2}$ It is usually triggered by nonnoxious stimuli and is characterized by involuntary and lancinating attacks of electric shock like pain., 4 According to the studies, 4.5 per 100,000 individuals suffer from trigeminal neuralgia with a female to male ratio of $2.5: 1$ and a positive family history in $5 \%$ of the cases. $^{2,5,6}$
According to the current recommendations, anticonvulsant medications such as carbamazepine or oxcarbazepine are usually used as first-line therapy for the initial relief of pain. ${ }^{4,7}$ Most of the patients remain asymptomatic for a period of six months, but in four out five individuals, the pain with re-appear after the six months and up to fifty percent of the individuals will become resistant to the pharmacological treatment or experience adverse effects of the medications hence requiring the surgical intervention. ${ }^{2,8}$

According to a study by Zakrzewska et al. regarding the effectiveness of the surgical intervention, 
$78 \%$ of the patients told that during the initial course of their disease, they would have preferred this treatment. ${ }^{9}$ Among the primary surgical interventions, there are microvascular decompression, percutaneous rhizotomy and stereotactic radiosurgery. ${ }^{10}$ Microvascular decompression (MVD) is an open method used when the surgeon needs to relieve the neurovascular compression and conserve the function of the trigeminal nerve. ${ }^{11}$ According to the studies, about $90 \%$ of the patients get pain free initially and above eighty percent remain pain relief after one year. Even after five years of surgery, $73 \%$ of the individuals don't experience the pain and remain pain free. ${ }^{2,12,13}$ Percutaneous rhizotomy is however noninvasive technique performed by approaching Gasserian ganglion by puncturing in the cheek with the help of a tew needle. ${ }^{14}$ According to the studies, about $90 \%$ of the patients get pain free initially and around $75 \%$ get pain relief after one year. However, after five years, about fifty percent of the patients present again with the history of recurrence of pain. ${ }^{2,15}$

This study was compared in order to compare the efficacy of radiofrequency rhizotomy (RFR) with microvascular decompression (MVD) in trigeminal neuralgia patients. The results of this study will be compared with national and international studies which will help the neurosurgeons approach and decide different surgical techniques in a diverse variety of patients.

\section{MATERIAL AND METHODS}

\section{Study Design and Sampling}

After taking the approval from the ethical committee, this randomized controlled trial (RCT) study was conducted in the neurosurgery department Lahore General Hospital Lahore for a period of one year June 2017 to June 2018. After taking the informed consent, detailed history and examination were performed. A total of 110 patients of either gender and between the ages of 35 to 65 years presenting with trigeminal neuralgia were included in this study.

Table 1: Descriptive statistics according to the groups.

\begin{tabular}{|c|c|c|c|c|}
\hline \multirow{2}{*}{ Group } & \multirow{2}{*}{ Age (Years) } & \multirow{2}{*}{$\begin{array}{c}\text { Disease } \\
\text { Duration } \\
\text { (Years) }\end{array}$} & \multicolumn{2}{|c|}{ Gender } \\
\hline & & & Male & Female \\
\hline RFR $(n=55)$ & $51.27 \pm 7.76$ & $2.63 \pm 1.86$ & $18(16.4 \%)$ & $37(33.6 \%)$ \\
\hline $\operatorname{MVD}(n=55)$ & $51.20 \pm 9.81$ & $3.722 \pm 1.67$ & $20(18.2 \%)$ & $35(31.8 \%)$ \\
\hline Total & $51.25 \pm 8.80$ & $3.18 \pm 1.85$ & $38(34.6 \%)$ & $72(65.4 \%)$ \\
\hline
\end{tabular}

\section{Inclusion Criteria}

The patients who had TGN refractory to the medication were also included in this study.

\section{Exclusion Criteria}

Patients who were pain-free after the pharmacological therapy or who presented with TGN due to secondary causes such as multiple sclerosis and tumors or those presenting with atypical TGN were excluded.

\section{Data Collection}

Demographic data were collected on a predefined questionnaire. A random distribution of all the patients were done using the lottery method in two equal groups, i.e. group-I patients underwent radiofrequency rhizotomy and group-II patients underwent microvascular decompression. After the procedure, the patients were kept under observation in the hospital and discharged once they were stable. Complications associated with the procedure were noted. Follow-up of the patients was done for six months. The efficacy was assessed in terms of complete pain relief.

\section{Data Analysis}

All the data were collected and explored using S.P.S.S Ver. 23.0. Mean and standard deviation were calculated for quantitative variables. Numbers and percentages were calculated for qualitative variables. In order to check the normality of the data ShapiroWilk test was used. Suitable statistical techniques were used. The Chi-square test was done in order to analyze the associations between qualitative variables. P-value of $\leq 0.05$ was taken as significant.

\section{RESULTS}

\section{Gender Incidence}

There were $38(34.6 \%)$ male and $72(65.4 \%)$ female patients (Table 1).

\section{Age Incidence}

Mean age of the patients was 51.25 \pm 8.80 years with an age range of $36-65$ years. Twenty-three $(20.91 \%)$ patients were between 35-45 years of age, $43(39.09 \%)$ were between $46-55$ years and $44(40.00 \%)$ patients were between 56-65 years of age. 
Table 2: Pain Improvement according different age groups.

\begin{tabular}{|c|c|c|c|c|c|c|c|}
\hline \multirow{2}{*}{ Groups } & \multirow{2}{*}{$\begin{array}{l}\text { Pain } \\
\text { Improvement }\end{array}$} & \multicolumn{3}{|c|}{ Age Groups (Years) } & \multirow{2}{*}{ Total } & \multirow{2}{*}{$\begin{array}{c}\text { \%age (Per } \\
\text { Group) }\end{array}$} & \multirow{2}{*}{$\begin{array}{c}\text { Overall } \\
\text { \%age }\end{array}$} \\
\hline & & $36-45$ & $46-55$ & $56-65$ & & & \\
\hline \multirow{4}{*}{$\operatorname{RFR}(\mathrm{n}=55)$} & Complete & 3 & 9 & 7 & 19 & 34.55 & 17.27 \\
\hline & Significant & 4 & 12 & 9 & 25 & 45.45 & 22.73 \\
\hline & Mild & 2 & 3 & 2 & 7 & 12.73 & 6.36 \\
\hline & No & 1 & 1 & 2 & 4 & 7.27 & 3.64 \\
\hline \multirow{4}{*}{$\operatorname{MVD}(n=55)$} & Complete & 7 & 12 & 11 & 30 & 54.55 & 27.27 \\
\hline & Significant & 4 & 3 & 7 & 14 & 25.45 & 12.73 \\
\hline & Mild & 1 & 3 & 5 & 9 & 16.36 & 8.18 \\
\hline & No & 1 & 0 & 1 & 2 & 3.64 & 1.82 \\
\hline \multicolumn{2}{|c|}{ Total } & 23 & 43 & 44 & 110 & -- & 100 \\
\hline
\end{tabular}

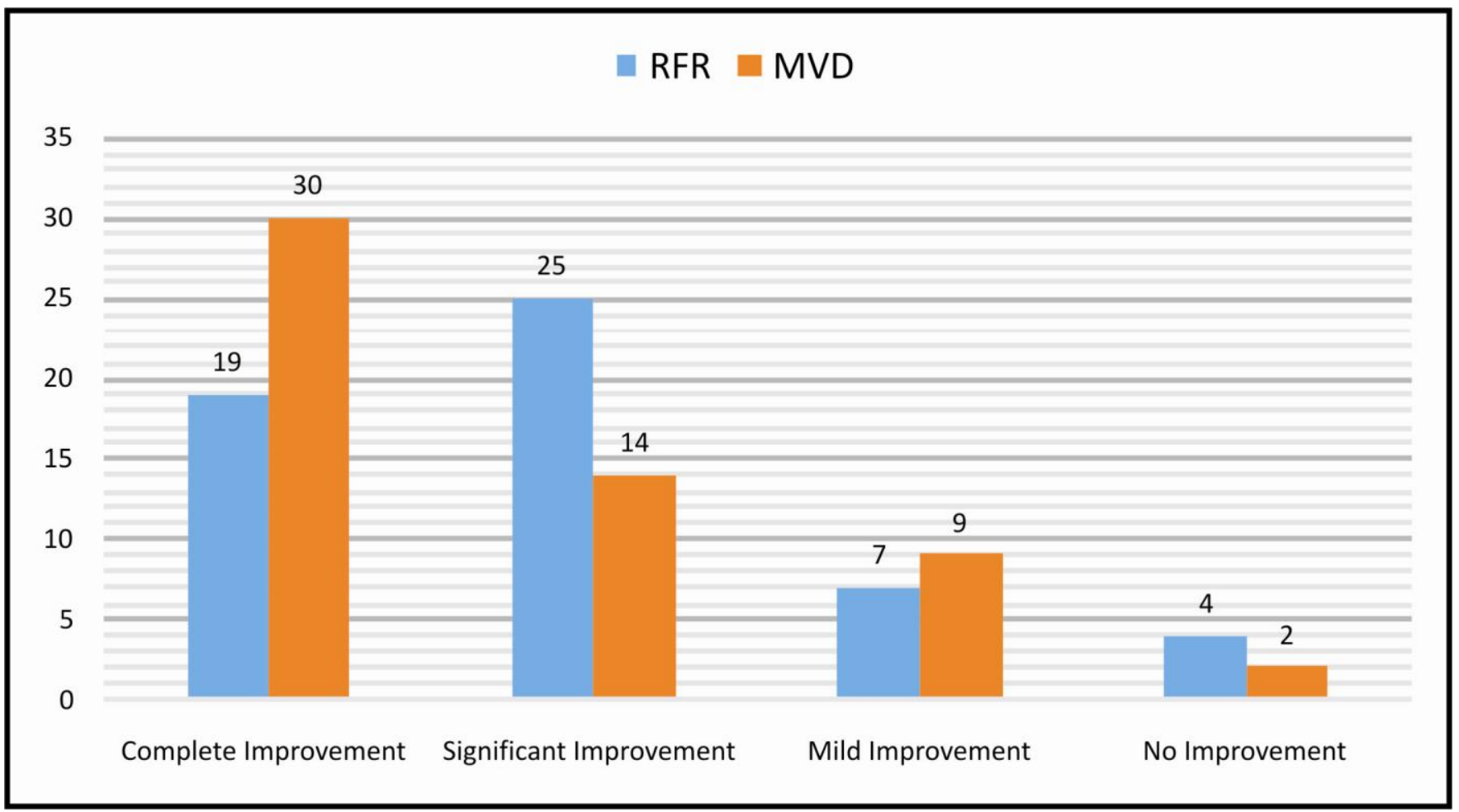

Graph 1: Efficacy of Rhizotomy and MVD in terms of pain relief.

\section{Duration of Pain}

The mean duration of disease was $3.18 \pm 1.85$ years, with a minimum duration of 6 months and a maximum duration of 6.50 years (Table 1$)$.

\section{Pain Relief}

Regarding the improvement in pain, in Group-I (RFR), Nineteen $(34.5 \%)$ patients were completely pain free at the end of six months, 25 (45.5\%) patients had 
significant pain relief i.e. they felt pain only once or twice, $7(12.7 \%)$ had mild improvement in the pain i.e. they felt the pain very often and 4 (7.3\%) patients had no improvement in the pain. In group-II (MVD), 30 $(54.5 \%)$ patients were completely pain free, 14 $(25.5 \%)$ had significant pain relief, 9 (16.4\%) had mild improvement and 2 (3.6\%) had no improvement in their pain (Chi-square $=6.49, \mathrm{p}=0.090)$ (Table 2 , Graph 1).

\section{Distribution of Pain}

In group-I patients, the pain was distributed as 27 $(49.09 \%)$ cases in V2 and V3, $15(27.27 \%)$ cases in $\mathrm{V} 1$ and $\mathrm{V} 2,8(14.54 \%)$ cases in $\mathrm{V} 2$ alone and 5 $(9.09 \%)$ cases in V1 alone. In group-II it was distributed as $26(47.279 \%)$ cases in V2 and V3, 13 $(23.63 \%)$ cases in V1 and V2, $9(16.36 \%)$ cases in V2 alone and $7(12.72 \%)$ cases in V1 alone.

\section{Complications}

In group-I (RFR) patients, 5 (9.09\%) patients developed a hematoma, $4(7.27 \%)$ patients developed Anesthesia dolorosa and 1 patient (1.81\%) developed painful dysesthesia. No other complications were seen. In group-II (MVD) patients, $3(5.45 \%)$ patients experienced CSF leak, 3 (5.45\%) patients had wound infection and 1 patient (1.81\%) developed aseptic meningitis.

\section{DISCUSSION}

The prime cause of the trigeminal neuralgia is demyelination of nerve afferents occurring due to neurovascular compression. The secondary trigeminal neuralgia may occur due to the multiple sclerosis or space-occupying pathologies. In our study, the mean age of the patients was $51.25 \pm 8.80$ years. This is in accordance with the study by Nanjappa et al., which states that the average age of onset of the trigeminal neuralgia is 53 years. ${ }^{16}$ Wang et al. reported the mean age of 63 years in patients who presented with trigeminal neuralgia and underwent microvascular decompression. ${ }^{11}$ The majority of the patients in our study were in $46-55$ years $(\mathrm{n}=43,39.09 \%)$ and $56-$ 65 years $(n=44,40.00 \%)$ group. In a study by Hung et al. $56.7 \%$ of patients were between $51-70$ years of age. ${ }^{17}$ These findings are similar to our findings. Nanjappa et al. stated that in their study, the majority was in between $51-60$ years. ${ }^{16}$ In our study, there was $34.6 \%$ male and $65.4 \%$ female patients and female to male ratio was 1.9:1. These findings are similar to a study by Hang et al., who reported $41.4 \%$ male and $58.6 \%$ female and a female to male of 1.42:1. ${ }^{17}$ Khan et al. reported female to male ratio of $1.30: 1{ }^{18}$

In our study, patients who underwent radiofrequency rhizotomy, eighty percent of the patients showed complete pain relief to significant pain relief, i.e. $45.5 \%$ had significant pain relief and $34.5 \%$ had complete pain relief. Nanjappa et al. performed rhizotomy on fifteen patients and reported that $80 \%$ of the patients showed excellent pain relief after a follow-up of six months. ${ }^{16}$ According to Xie et al. $87 \%$ of the patients reported pain relief after undergoing rhizotomy. ${ }^{19}$ In our study, $12.7 \%$ of the patients showed mild improvement and $7.3 \%$ showed no improvement.In a study by Kanpolat et al., the $97.6 \%$ of the patients had complete pain relief immediately after the procedure, but at the end of six months, $7.7 \%$ of the patients started feeling again and again. ${ }^{20}$ Tronnier et al., also documented in their study that the fifty percent of the patients who underwent rhizotomy started feeling pain again after their first follow-up. ${ }^{21}$

The patients who underwent microvascular decompressions and $54.5 \%$ were completely pain-free and $25.5 \%$ had significant pain relief. Khan et al., noticed in their study that $68 \%$ of the patients who undertook microvascular decompression were completely pain-free and $26.45 \%$ had significant pain relief. ${ }^{18}$ Tronnier et al, documented that $76.4 \%$ of the patients remained pain-free after two years of microvascular decompression. ${ }^{21}$ Pagni et al. also acknowledged that patients undergoing microvascular decompression showed much better results than anyother technique. ${ }^{22}$ In our study, $3.6 \%$ patients who undertook microvascular decompression experienced no improvement in their pain. This is in accordance with the findings by Khan et al. who documented that $5.6 \%$ of the patients had no improvement after MVD. ${ }^{18}$

\section{CONCLUSIONS}

Microvascular decompression had better results than a radiofrequency rhizotomy in patients presenting with trigeminal neuralgia regarding excellent pain relief and fewer complications.

\section{LIMITATIONS}

We didn't follow the patients after the six months of the procedure. An extensive follow-up with larger number of patients should be carried out. 


\section{Additional Information}

Disclosures: Authors report no conflict of interest.

Human Subjects: Consent was obtained by all patients/ participants in this study.

Conflicts of Interest:

In compliance with the ICMJE uniform disclosure form, all authors declare the following:

Financial Relationships: All authors have declared that they have no financial relationships at present or within the previous three years with any organizations that might have an interest in the submitted work.

Other Relationships: All authors have declared that there are no other relationships or activities that could appear to have influenced the submitted work.

\section{Address for Correspondence Dr. Abdul Majid PGMI/Lahore General Hospital Lahore, Pakistan Email: neurosurgeon1974@gmail.com}

\section{REFERENCES}

1. Li Y, Mao F, Cheng F, Peng C, Guo D, Wang B. A meta-analysis of endoscopic microvascular decompression versus microscopic microvascular decompression for the treatment for cranial nerve syndrome caused by vascular compression. World neurosurgery, 2019.

2. Straus DC, Ko AL, Sekhar LN. Trigeminal Neuralgia. Principles of Neurological Surgery: Elsevier, 2018; 745-52.

3. Gornitsky M, Elsaraj SM, Canie O, Mohit S, Velly AM, Schipper HM. Greater palatine block for V2 trigeminal neuralgia: Case report. Special Care in Dentistry, 2019; 39 (2): 208-13.

4. Bendtsen L, Zakrzewska JM, Abbott J, Braschinsky M, Di Stefano G, Donnet A, et al. European Academy of Neurology guideline on trigeminal neuralgia. European journal of neurology, 2019; 26 (6): 831-49.

5. Jafree DJ, Zakrzewska JM. Long-term pain relief at five years after medical, repeat surgical procedures or no management for recurrence of trigeminal neuralgia after microvascular decompression: analysis of a historical cohort. British journal of neurosurgery, 2019; 33 (1): 31-6.

6. Ravina K, Strickland BA, Rennert RC, Bakhsheshian J, Russin JJ, Giannotta SL. Revision Microvascular Decompression for Trigeminal Neuralgia and Hemifacial Spasm: Factors Associated with Surgical Failure. Journal of Neurological Surgery Part B: Skull Base, 2019; 80 (01): 031-9.

7. Tanaka T, Shiiba S, Yoshino N, Harano N, Sago T, Kito $\mathrm{S}$, et al. Predicting the therapeutic effect of carbamazepine in trigeminal neuralgia by analysis of neurovascular compression utilizing magnetic resonance cisternography. International journal of oral and maxillofacial surgery, 2019; 48 (4): 480-7.

8. Shah RJ, Padalia D. Sphenopalatine Ganglion Radiofrequency Thermocoagulation. Stat Pearls. Treasure Island (FL), 2019.

9. Zakrzewska JM, Linskey ME. Trigeminal neuralgia. BMJ. 2014; 348: g474.

10. Montano N, Conforti G, Di Bonaventura R, Meglio M, Fernandez E, Papacci F. Advances in diagnosis and treatment of trigeminal neuralgia. Therapeutics and clinical risk management, 2015; 11: 289.

11. Wang DD, Raygor KP, Cage TA, Ward MM, Westcott S, Barbaro NM, et al. Prospective comparison of longterm pain relief rates after first-time microvascular decompression and stereotactic radiosurgery for trigeminal neuralgia. Journal of neurosurgery, 2018; 128 (1): 68-77.

12. Jafree DJ, Williams AC, Zakrzewska JM. Impact of pain and postoperative complications on patientreported outcome measures 5 years after microvascular decompression or partial sensory rhizotomy for trigeminal neuralgia. Acta neurochirurgica, 2018; 160 (1): 125-34.

13. Cruccu G, Finnerup NB, Jensen TS, Scholz J, Sindou $M$, Svensson $P$, et al. Trigeminal neuralgia: new classification and diagnostic grading for practice and research. Neurology, 2016; 87 (2): 220-8.

14. Asplund P, Blomstedt P, Bergenheim AT. Percutaneous balloon compression vs percutaneous retrogasserian glycerol rhizotomy for the primary treatment of trigeminal neuralgia. Neurosurgery, 2015; 78 (3): 4218.

15. Staudt MD, Rivera M, Miller JP. Percutaneous procedures for trigeminal neuralgia. Diagnosis and Management of Head and Face Pain: Springer, 2018: p. 221-33.

16. Nanjappa M, Kumaraswamy S, Keerthi R, Ashwin D, Gopinath A, Reyazulla M, et al. Percutaneous radiofrequency rhizotomy in treatment of trigeminal neuralgia: a prospective study. Journal of maxillofacial and oral surgery, 2013; 12 (1): 35-41.

17. Huang C, Wan Z, Wan C, Li Y, Zhong R. Clinical factors and safety of microvascular decompression in the treatment of trigeminal neuralgia. Biomedical Research, 2018; 29 (9): 1845-51.

18. Khan SA, Khan B, Khan AA, Afridi EAK, Mehmood S, Muhammad G, et al. Microvascular decompression for trigeminal neuralgia. Journal of Ayub Medical College Abbottabad, 2015; 27 (3): 539-42.

19. Xie E, Garzon-Muvdi T, Bender M, Doshi T, Carson B, Lim M, et al. Association Between Radiofrequency Rhizotomy Parameters and Duration of Pain Relief in Trigeminal Neuralgia Patients with Recurrent Pain. World neurosurgery, 2019. 
20. Kanpolat Y, Savas A, Bekar A, Berk C. Percutaneous controlled radiofrequency trigeminal rhizotomy for the treatment of idiopathic trigeminal neuralgia: 25-year experience with 1600 patients. Neurosurgery, 2001; 48 (3): 524-34.

21. Tronnier VM, Rasche D, Hamer J, Kienle A-L, Kunze S. Treatment of idiopathic trigeminal neuralgia: comparison of long-term outcome after radiofrequency rhizotomy and microvascular decompression. Neurosurgery, 2001; 48 (6): 1261-8.

22. Pagni CA, Fariselli L, Zeme S. Trigeminal neuralgia. Non-invasive techniques versus microvascular decompression. It is really available any further improvement? Reconstructive Neurosurgery: Springer, 2008: 27-33.

\begin{tabular}{|c|c|c|c|}
\hline \multicolumn{4}{|c|}{ AUTHORSHIP AND CONTRIBUTION DECLARATION } \\
\hline Sr.\# & Author's Full Name & Intellectual/Contribution to Paper in Terms of: & \\
\hline 1. & $\begin{array}{l}\text { Abdul Majid } \\
\text { (Main/Principal Author). }\end{array}$ & 1. Proposed topic, and data collection, & $\begin{array}{l}\text { Signature by the } \\
\text { author(s) }\end{array}$ \\
\hline 2. & $\begin{array}{l}\text { Muhammad Farooq } \\
\text { (2nd Author) }\end{array}$ & $\begin{array}{l}\text { 2. Data collection, calculations and manuscript } \\
\text { writing }\end{array}$ & \\
\hline 3. & $\begin{array}{l}\text { Muhammad Shakir } \\
\text { (3rd Author) }\end{array}$ & $\begin{array}{l}\text { 3. Analysis of data, interpretation of results and } \\
\text { Literature review }\end{array}$ & De= \\
\hline 4. & $\begin{array}{l}\text { Zubair Mustafa Khan } \\
\left(4^{\text {th }} \text { author }\right)\end{array}$ & $\begin{array}{l}\text { 4. Paper writing, referencing, Data Calculations and } \\
\text { quality insurer }\end{array}$ & 290 \\
\hline 5. & $\begin{array}{l}\text { Sajid Iqbal } \\
\left.\text { ( } 5^{\text {th }} \text { Author }\right)\end{array}$ & 5. Study Design and methodology & \\
\hline
\end{tabular}

Date of Submission: 20-07-2019

Date of Revision: 16-08-2019

Date of Online Publishing: 25-09-2019

Date of Print: 30-09-2019 